\title{
ANALISA KERUSAKAN COLLET PADA MESIN COILLING PEMBUAT SPRING SPEEDOMETER CABLE DAN UPAYA PENCEGAHAN
}

\author{
Andri Lesmana ${ }^{1}$ \\ ${ }^{1}$ Program Studi Teknik Mesin, Universitas Pamulang, Jl. Surya Kencana No. 1, Tangerang Selatan, Indonesia \\ Email : dosen01278@unpam.ac.id
}

Masuk : 26 Februari 2019

Direvisi : 16 April 2019

Disetujui : 29 April 2019

\begin{abstract}
Abstraksi : Analisis kegagalan dan kerusakan komponen mesin Coilling di industri manufacture automotive salah satu ilmu yang dapat dipelajari dan digunakan untuk menganalisa suatu komponen mesin Coilling yang mengalami kegagalan dan kerusakan komponen mesin patah atau failure, dengan mencari akar penyebab kegagalannya (root causes of problems) tujuannya untuk memberikan rekomendasi penyebab Utama kegagalan dan kerusakan komponen mesin Coilling, Agar tidak terjadi kesalahan yang berulang.

Hasil analisis ini harus dilakukan penelitian mengenai analisis kegagalan dan kerusakan sebuah collet pada mesin coilling pembuat spring speedometer cable yang menggunakan material dasar collet steel S45C, collet pada mesin coilling mengalami kegagalan dan kerusakan patah pada saat proses produksi spring speedometer cable.

Untuk mengetahui hasil penelitian telah dilakukan pengujian komposisi kimia, pengujian kekerasan, pengujian struktur mikro dan pengamatan perubahan sifat mekanis collet. Penyebab utama kerusakan adalah fatigue yang diakibatkan oleh beban siklus dengan kondisi high nominal stress dan dapat digunakan untuk pengembangan kualitas collet serta optimasi usaha pencegahan perpatahan pada collet meliputi perbaikan desain, material, manufaktur dan cara pemasangan serta penerapan sistem manajemen pemilihan material yang tepat.
\end{abstract}

Kata Kunci : Analisa Kerusakan, Collet, Mesin Coilling, Spring Speedometer Cable, Pencegahan

Abstract : Analysis of failure and damage of Coilling machine components in the automotive manufacturing industry is one of the sciences that can be studied and used to analyze a Coilling machine component that has failed and damaged a broken machine component or failure, by finding the root causes of problems. to provide recommendations for the main causes of failure and damage to Coilling engine components, so that there are no recurring errors.

The results of this analysis must be carried out research on the analysis of failure and damage to a collet on the coilling machine spring speedometer cable maker using S45C collet steel base material, collet on the coilling machine failed and broken damage during the spring speedometer cable production process.

To find out the results of the study, chemical composition testing, hardness testing, microstructure testing and observation of changes in mechanical properties of collets were carried out. The main cause of damage is fatigue caused by cycle loads with nominal high stress conditions and can be used to develop collet quality and optimization of fracture prevention efforts in collets including improvements in design, material, manufacturing and installation methods and the application of appropriate material selection management systems.

Keywords : Damage Analysis, Collet, Coilling Machine, Spring Speedometer Cable, Prevention 
Jurnal Teknik Mesin: CAKRAM 2019

Andri Lesmana, Analisa Kerusakan Collet pada Mesin Coilling Pembuat Spring Speedometer Cable dan Upaya Pencegahan

\section{PENDAHULUAN}

Pemeliharaan dan keandalan (Maintenance and reliability) merupakan aktivitas yang berkaitan untuk mempertahankan peralatan sistem kerja mesin dalam kondisi baik untuk waktu tertentu sehingga tidak mengganggu proses produksi.[1]

Collet merupakan alat pencekam proses manufaktur untuk memproduksi part - part kendaraan bermotor yang memiliki keseragaman dan jenis yang tidak terbatas. Proses kerja collet menggunakan sistem hidrolik pneumatik gaya tekan tinggi sehingga collet tersebut mencekam matrial proses.[2]

Mesin coilling merupakan mesin pembuat spring speedometer cable yang menggunakan motor dinamo, dalam proses manufaktur automotive sehingga menghasilkan produk kualitas tinggi untuk part sepeda motor maupun mobil. Saat ini mesin coilling digunakan untuk proses produksi pembuatan spring speedometer cable yang bergerak di bidang manufaktur automotive.[3]

Tujuan penelitian ini agar dapat memberikan informasi secara aktual tentang penyebab kerusakan collet pada mesin coilling pembuat spring speedometer cable sehingga bisa memberikan rekomendasi yang aman dalam penggunaan material, proses manufaktur dan sistem operasional serta upaya pencegahan kerusakan yang sama atau yang lebih fatal.

\section{METODOLOGI}

Sebelum melakukan penelitian penyebab terjadinya kerusakan dan kegagalan operasi collet alat pencekam dilakukan beberapa pengujian, Hal ini bertujuan untuk mencari penyebab dominan kerusakan pada collet tersebut. Metode yang akan dilakukan dalam penelitian ini dapat dilihat pada diagram alir berikut ini :

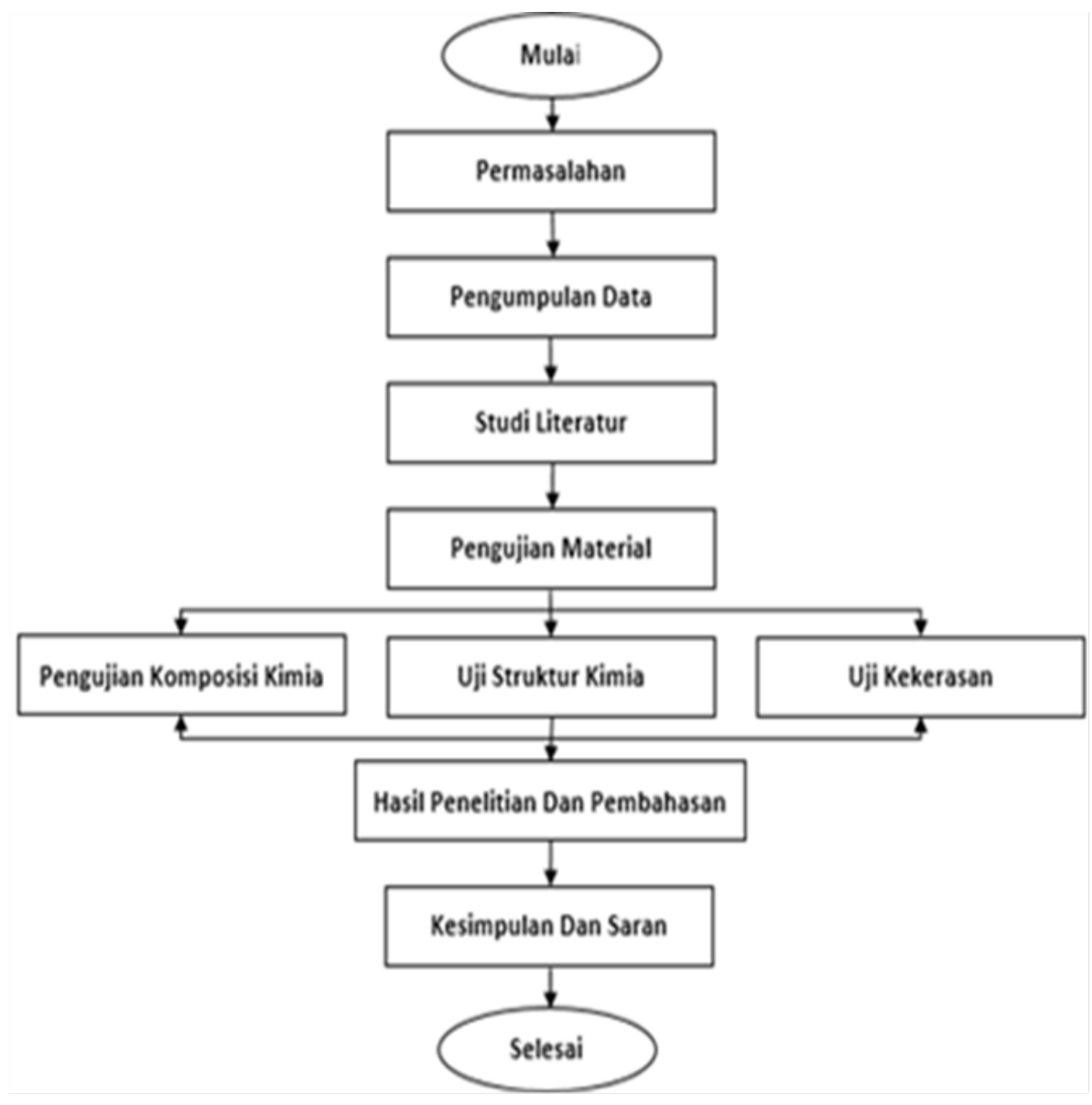

Gambar 1 Metode Penelitian Yang Akan Dilakukan 
Jurnal Teknik Mesin: CAKRAM 2019

Andri Lesmana, Analisa Kerusakan Collet pada Mesin Coilling Pembuat Spring Speedometer Cable dan Upaya Pencegahan

Penjelasan pada diagram alir penelitian adalah sebagai berikut :

\section{Tahap Awal Penelitian}

Pada tahap ini akan dilakukan review terhadap collet yang meliputi analisis kegagalan patah pada bagian atas (leher Pencekam) collet, adanya radius pada bagian atas (leher Pencekam) collet dan patah pada bagian tengah celah badan collet.

\section{Tahap Penelitian}

Pengamatan visual yaitu dengan melakukan pemeriksaan secara langsung terhadap material collet yang mengalami kerusakan dan kegagalan patah. Untuk mendapatkan data yang lebih akurat dilakukan pengambilan photo pada collet yang berhubungan dengan sistem operasi mesin coilling pembuat spring speedometer cable.

\section{Dilakukan Uji Material}

Pada tahap penelitian ini akan dilakukan pengujian material :
a. Pengujian Komposisi Kimia
b. Pengujian Struktur Mikro
c. Pengujian Kekerasan

4. Dilakukan Uji Komposisi Kimia

Pemeriksaan komposisi kimia bertujuan untuk mengetahui komposisi material collet sehingga dapat dilakukan komparasi antara material, desain dengan komposisi material collet secara aktual.

5. Dilakukan Uji Struktur Mikro

Pengujian struktur mikro dilakukan untuk mengetahui adanya unsur cacat material, perubahanan struktur material, jenis perpatahan yang terjadi dan sebagai referensi bahwa collet tersebut layak digunakan kembali atau tidak.

\section{Dilakukan Uji Kekerasan}

Uji kekerasan (hardness testing) dimaksudkan untuk mengetahui daya tahan collet terhadap deformasi plastis, ketahanan aus serta abrasif pada material.

\section{HASIL DAN PEMBAHASAN}

Pada saat proses produksi sering mengalami kegagalan dan kerusakan pada komponen collet pencekam plat wire pembuat spring speedometer cable selalu terjadi kegagalan dan kerusakan patah, oleh karena itu kekuatan material dari collet harus benar-benar diperhatikan. salah satu hal penting yang perlu diperhatikan dari pembuatan collet spring speedometer cable selain desain adalah material yang sesuai standart.

\section{Dilakukan Uji Komposisi Kimia}

Uji komposisi kimia dilakukan agar dapat diketahui komposisi material dasar collet S45C, sehingga dapat dilakukan analisa pada material collet S45C secara aktual. Dari hasil pengujian komposisi kimia, material collet S45C mempunyai kadar Ferrous (Fe) sebesar 98.0\%, Carbon (C) sebesar $0.480 \%$, Silicone (Si) sebesar 0.293 \%, Mangan (Mn) sebesar 0.636 \%, Crohomium (Cr) sebesar $0.345 \%$. Material collet $S 45 C$ ini memiliki sifat tahan untuk dilakukan proses pemanasan atau proses (Heattreatment) agar mendapatkan nilai kekerasan dan keuletan (Ductility) yang lebih baik. Spesifikasi material ini banyak digunakan sebagai alat perkakas dalam dunia industri. Komposisi dari material collet S45C secara rinci bisa diketahui pada Tabel 1.

Tabel 1 Hasil Uji Komposisi Kimia (Chemical Composition)

\begin{tabular}{|c|c|c|}
\hline \multirow{2}{*}{ NO } & \multirow{2}{*}{ UNSURE } & RESULT (wt \%) \\
\cline { 3 - 3 } & & COLLET \\
\hline 1 & Fe & 98.0 \\
\hline 2 & C & 0.480 \\
\hline
\end{tabular}


Jurnal Teknik Mesin: CAKRAM 2019

Andri Lesmana, Analisa Kerusakan Collet pada Mesin Coilling Pembuat Spring Speedometer Cable dan Upaya Pencegahan

\begin{tabular}{|c|c|l|}
\hline 3 & Si & 0.293 \\
\hline 4 & Mn & 0.636 \\
\hline 5 & Cr & 0.345 \\
\hline 6 & Ni & 0.0052 \\
\hline 7 & Mo & 0.0188 \\
\hline 8 & Cu & 0.0148 \\
\hline 9 & Al & 0.0190 \\
\hline 10 & V & 0.0091 \\
\hline 11 & Ti & 0.0032 \\
\hline 12 & S & 0.0069 \\
\hline 13 & P & 0.0345 \\
\hline 14 & Co & 0.0160 \\
\hline 15 & Nb & 0.0234 \\
\hline 16 & W & 0.0333 \\
\hline
\end{tabular}

\section{Dilakukan Uji Struktur Mikro}

Pengujian struktur mikro bertujuan dilakukan untuk mengetahui adanya unsur cacat material, perubahanan struktur material, jenis perpatahan yang terjadi dan sebagai referensi bahwa collet tersebut layak digunakan kembali atau tidak.

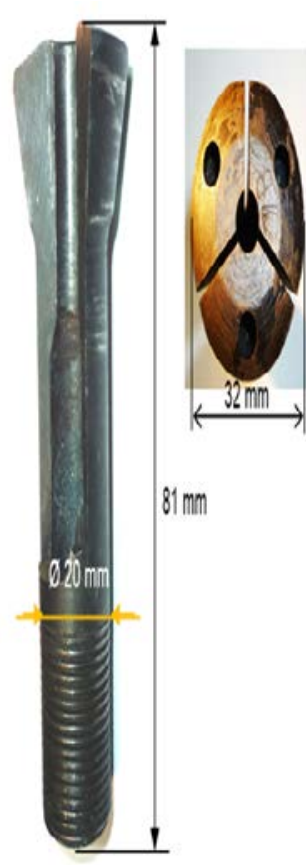

(a)

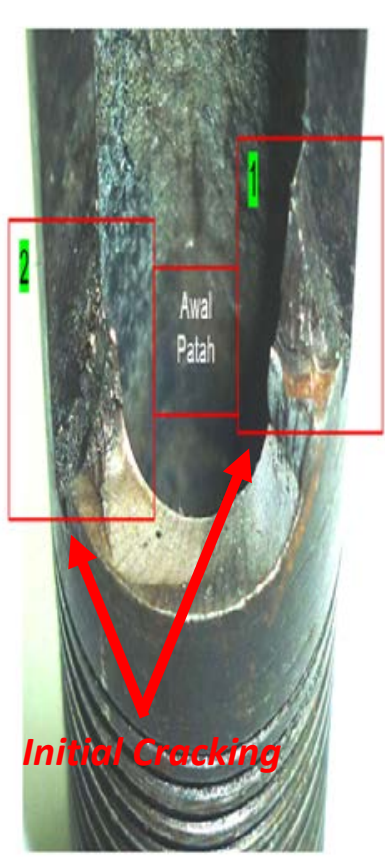

(b)

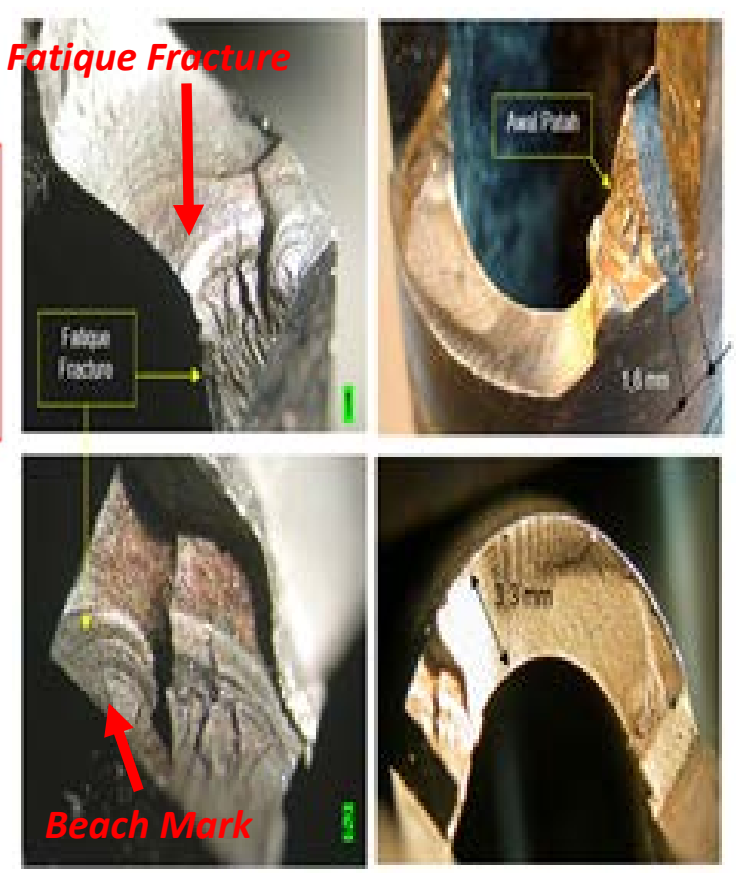

(c)

Gambar 2 (a) Hasil Pemeriksaan Pada Sampel Mengalami Patah Dibagian Ujung Celah Badan Collet (b) Terlihat Initial Crack Berupa Patah Lelah (Fatique Fracture) (c) Adanya Garis Pantai (Beach Mark) Dan Dilanjutkan Penjalaran Patah 
Jurnal Teknik Mesin: CAKRAM 2019

Andri Lesmana, Analisa Kerusakan Collet pada Mesin Coilling Pembuat Spring Speedometer Cable dan Upaya Pencegahan
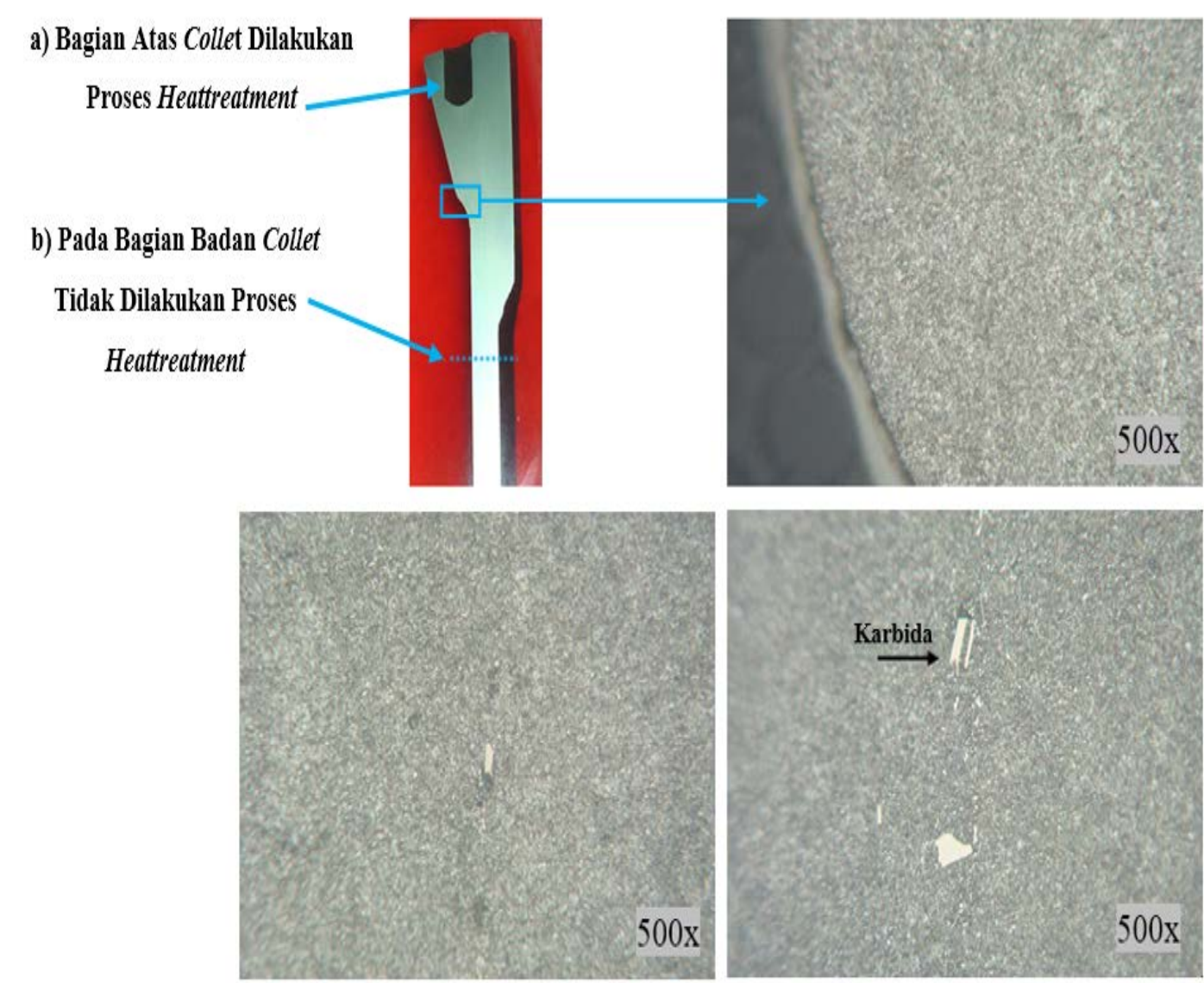

Gambar 3 (a) Pemeriksaan Sampel Pada Bagian Kepala (Atas Pencekam) (b) Pemeriksaan Sampel Pada Bagian Badan Collet (Bawah) Tidak Dilakukan Proses Heattreatment (Material Dasar), Struktur Mikro Berupa Martensit Dan Butir Karbida Menyebar Merata Nilai Kekerasan 492-612 HV
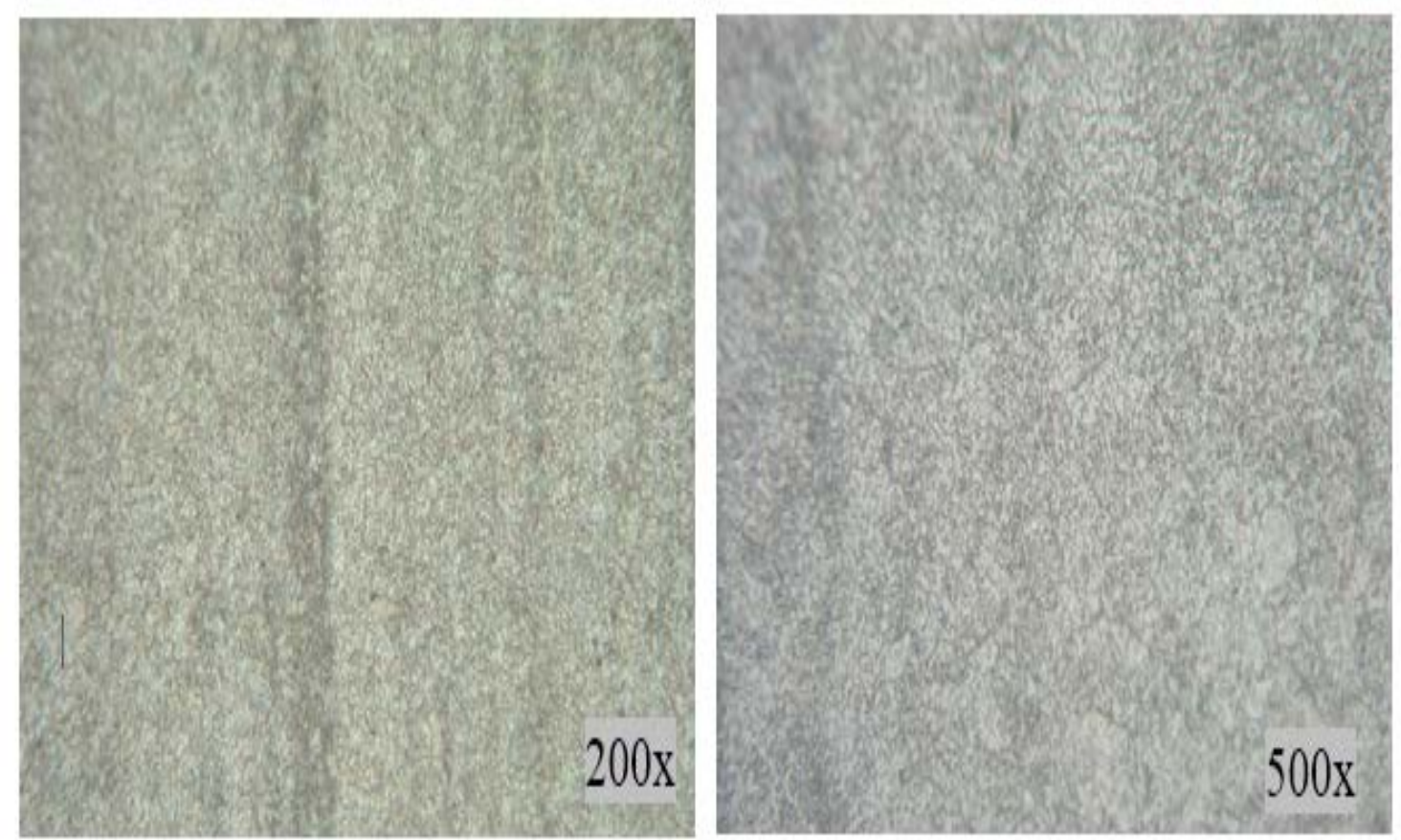

Gambar 4 Struktur Mikro Berupa Bainit - Austenit Dan Butir Karbida Menyebar Merata. Nilai Kekerasan 199 - 216 HV 
Jurnal Teknik Mesin: CAKRAM 2019

Andri Lesmana, Analisa Kerusakan Collet pada Mesin Coilling Pembuat Spring Speedometer Cable dan Upaya Pencegahan

\section{a. Dilakukan Uji Kekerasan}

Uji kekerasan (hardness testing) dimaksudkan untuk mengetahui daya tahan collet terhadap deformasi plastis, ketahanan aus serta abrasif pada material, pengujian kekerasan dilakukan 9 titik pengujian pada bagian atas collet (pencekam) yang di heattreatment, dan bagian badan (Bawah) collet yang tidak di heattreatment (Material Dasar) .

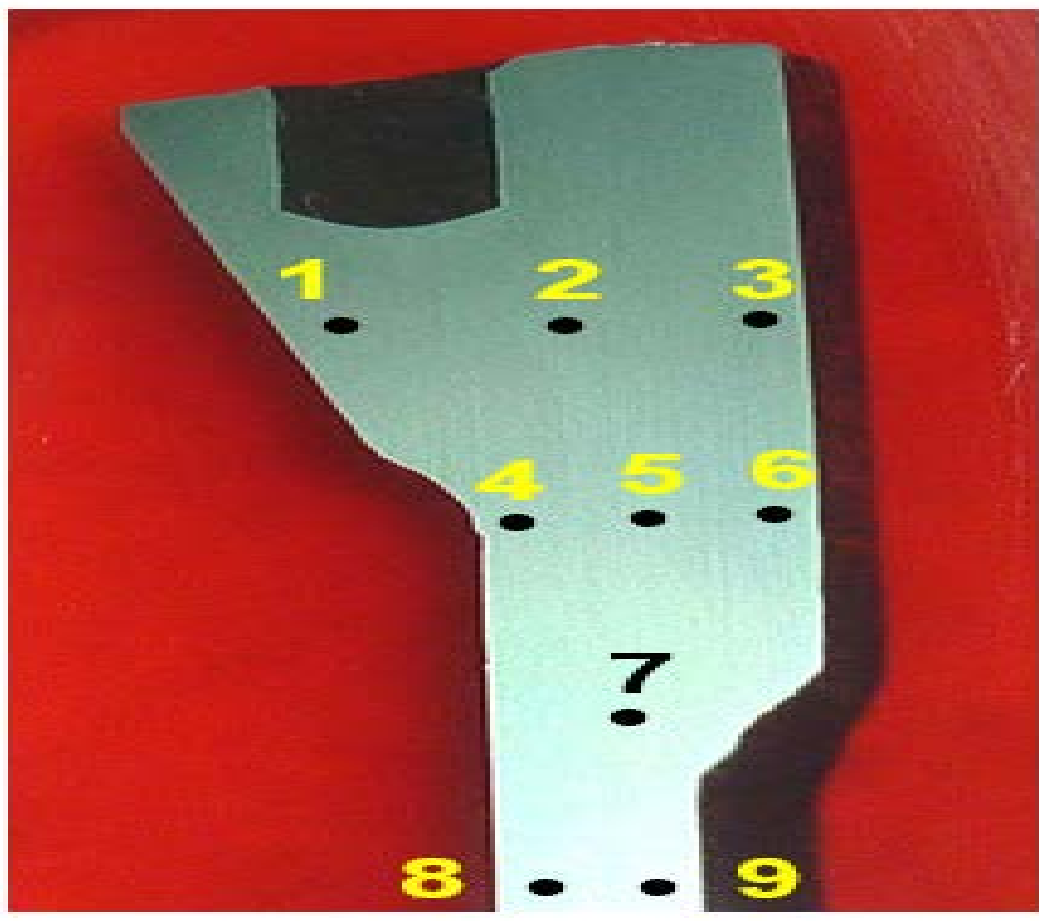

Gambar 5 Hasil Pengujian Kekerasan 9 Titik

Tabel 2 Hasil Pengujian Kekerasan

\begin{tabular}{|c|c|c|}
\hline \multirow{2}{*}{ NO. } & NILAI KEKERASAN (HV) & \multirow{2}{*}{ KETERANGAN } \\
\cline { 2 - 2 } & SAMPEL & a) Hasil Sempel Pengujian Pada \\
Titik 1 Sampai Dengan Titik 6 \\
Dilakukan Proses Heattreatment \\
(bagian atas pencekam), \\
S
\end{tabular}


Jurnal Teknik Mesin: CAKRAM 2019

Andri Lesmana, Analisa Kerusakan Collet pada Mesin Coilling Pembuat Spring Speedometer Cable dan Upaya Pencegahan

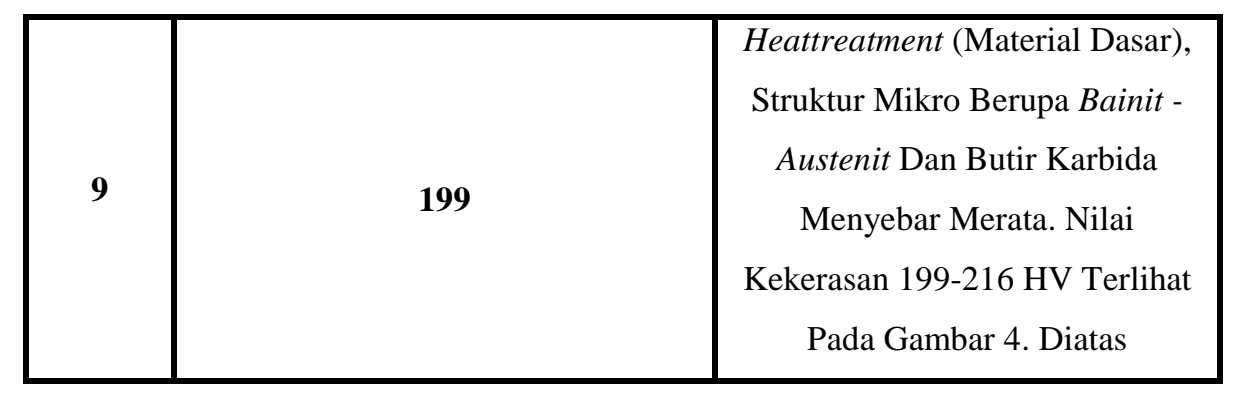

\section{KESIMPULAN DAN SARAN}

Berdasarkan hasil penelitian ini dapat disimpulkan beberapa hal mengenai kerusakan collet pada mesin coilling pembuat spring speedometer cable sebagai berikut :

1. Retakan awal (crack initiation) terjadi dikarenakan adanya konsentrasi tegangan pada daerah atas collet yang memiliki sudut.

2. Proses terjadinya kegagalan dan kerusakan pada collet dimulai dengan terjadinya retakan yang berawal dari sudut daerah atas collet (crack initiation) dan kemudian terbentuk rambatan retak (crack propagation) akhirnya patah seluruhnya dibagian sisi collet (final rupture) merupakan patah lelah.

3. Diarenakan adanya retakan dapat mengakibatkan patahnya collet dan terjadinya konsentrasi tegangan berulang pada badan collet, momen bending yang bekerja pada collet meliputi momen torsi yang bekerja pada collet.

Berdasarkan hasil penelitian ini ada beberapa saran yang perlu dipertimbangkan dari kerusakan collet pada mesin coilling pembuat spring speedometer cable sebagai berikut :

1. Perlu dilakukan proses perlakuan panas (heattreatment) pada bagian atas pencekam dan bagian badan collet agar mendapatkan nilai kekerasan dan keuletan yang lebih baik lagi untuk mengantisipasi adanya indikasi kegagalan komponen collet terutama pada bagian yang berhubungan dengan rumah collet.

2. Perlu dilakukan proses tempering setelah collet di heattreatment agar mendapatkan hasil keuletan yang diinginkan dan pengkajian kembali secara lebih detail dalam pemilihan material, desain dan pemasangan collet.

3. Upgrade material dan perlu ditambahkan komposisi paduan (alloy) tertentu pada proses manufaktur collet serta perlakuan panas (surfacetreatment) pada body collet agar lebih tahan terhadap pengaruh gesekan namun tidak mempengaruhi fungsi pencekamnya.

\section{DAFTAR PUSTAKA}

[1]Dhillon, B.S. 2006. Maintanability, Maintenance, and Realibility for Engineers. Taylor and Francis Group. New York : LLC

[2]Satyarini, E. (2013). Optimalisasi Sifat-Sifat Mekanik Material S45C. Skripsi. Fakultas Teknologi Industri, Program Studi Teknik Industri, Universitas Atma Jaya Yogyakarta

[3]Wiawan, R, G. (2018). Analisis Dan Usulan Perbaikan Efektivitas Kinerja Mesin Coiling Berdasarkan Nilai Overall Equipment Effectiveness Di PT. Indonesia Prima Spring Tbk. Skripsi. Fakultas Teknik, Program Studi Teknik Indutri, Universitas Muhammadiyah Gresik

[4]Anrinal. (2013). Metalurgi Fisik. Padang: Andi.

[5]D, N. A. (2003). Struktur dan Sifat Mekanis Material Logam. Jakarta: ISTN Jakarta.

[6]Daryanto. (2010). Ilmu Metalurgy. Bandung: Satu nusa. 